\title{
Espacio y Desarrollo $\mathrm{N}^{\circ} 34,2019$, pp. 87-116 (ISSN 1016-9148) https://doi.org/10.18800/espacioydesarrollo.201902.004
}

\section{DESCENTRALIZACIÓN Y RECONFIGURACIÓN PRODUCTIVA EN LA INDUSTRIA AUTOMOTRIZ MEXICANA}

\author{
Rosa Silvia Arciniega Arce \\ Departamento de Sociología. División de Ciencias Sociales y Humanidades \\ Universidad Autónoma Metropolitana Sede Iztapalapa. Ciudad de México \\ rsarciniega@hotmail.com
}

Fecha de recepción 15/06/2019

Fecha de aceptación 21/05/2020

\section{Resumen}

En un contexto de cambios en la economía internacional, México se ubica actualmente como el primer país productor de vehículos y autopartes en América Latina, séptimo productor de vehículos en el mundo. El sector automotriz constituye uno de los ejes estratégicos de la economía mexicana. Desde los ańos noventa muestra un dinamismo particular con la firma del Tratado de Libre Comercio con América del Norte, y después de 2009 presenta una nueva etapa de expansión con apertura de nuevas plantas, la llegada de mayor inversión extranjera directa, crecimiento de la producción, incremento del comercio internacional y exportaciones.

En las últimas décadas se configura un modelo específico de organización industrial y una nueva organización territorial, cuando se generaliza la descentralización productiva, con un número creciente de actividades realizadas en establecimientos separados pertenecientes a empresas diversas. La producción de componentes y partes se externaliza hacia proveedores, se disocian tareas antes integradas y se organizan redes de empresas. Adquieren importancia las empresas proveedoras que concentran el $90 \%$ del empleo y $70 \%$ de las remuneraciones del sector. Es importante incidir en la presencia de este segmento de la industria automotriz, pues en los últimos años adquiere un rol protagónico. México se posiciona como el quinto exportador de autopartes en el mundo.

Considerando la importancia de los procesos de descentralización y reorganización industrial el objetivo es presentar un panorama general del sector automotriz en México, incidiendo en el segmento de proveedoras.

La metodología que utilizamos implica la revisión y seguimiento de variables estadísticas de producción, exportación, inversión extranjera directa y empleo. También se basa en resultados de investigación que implican revisión de literatura sobre las proveedoras.

Palabras clave: Industria automotriz México, descentralización, reconfiguración productiva, proveedoras de autopartes, nueva división del trabajo. 


\section{Productive Decentralization and Productive Reconfiguration in the Mexican Auto- motive Industry}

\section{Abstract}

In a context of changes in the international economy, Mexico is positioned currently as the first vehicle and auto parts producing country in Latin America, seventh producer of vehicles in the world. The automotive sector constitutes one of the strategic axes of the Mexican economy. Since the nineties it has shown a particular dynamism with the signing of the North American Free Trade Agreement and after 2009 presents a new stage of expansion with the opening of new plants, the arrival of more foreign direct investment, growth of production, an increase in international trade and exports.

In recent decades a specific model of industrial organization and a new territorial organization has been configured, when productive decentralization is generalized, with a growing number of activities carried out in separate establishments that belong to various companies. The production of components and parts is externalized towards suppliers, tasks that used to be integrated get dissociated and are organized in company networks. The supplier companies acquire importance as they concentrate $90 \%$ of employment and $70 \%$ of the sector's compensation. It is important to focus on the presence of this segment of the automotive industry, as in recent years it acquires a main role. Mexico is positioned as the fifth auto part exporter in the world. Considering the importance of the decentralization process and industry reorganization, the objective is to present a general outlook of the Mexican automotive sector, focusing on the supplier segment.

The methodology that we utilize implies the review and following of statistical variables of production, export, foreign direct investment and employment. It is also based on results of research that implies review of literature about suppliers.

Keywords: automotive industry Mexico, decentralization, productive reconfiguration, auto parts suppliers, new division of labor. 


\section{INTRODUCCIón}

En el contexto de la globalización, se configura una nueva forma o modelo específico de organización industrial, con la aparición de un número creciente de actividades realizadas en establecimientos separados pertenecientes a empresas diversas. La producción de componentes y partes se externaliza hacia proveedores, se disocian tareas antes integradas y se organizan redes de empresas. Con ello adquieren importancia la subcontratación y las empresas proveedoras que organizan redes de vínculos inter e intra empresariales, lo que en conjunto se denomina descentralización productiva (Méndez y Caravaca, 1996).

En las últimas décadas, en la industria automotriz de México se consolida esta nueva forma de organización industrial donde resalta el protagonismo de las empresas proveedoras ${ }^{1}$. En México, las empresas proveedoras de autopartes representan el 60\% del valor agregado, $70 \%$ de las remuneraciones y $90 \%$ del personal ocupado en la industria automotriz nacional. Considerando los empleos, a diciembre de 2015, el sector automotriz era responsable de 875388 empleos directos, de los cuales 81927 $(9,35 \%)$ corresponden a la fabricación de automóviles y camiones y $793456(90,6 \%)$ se ubican en el sector de autopartes (Arciniega, 2018). México se ubica actualmente como el primer país productor de vehículos y autopartes en América Latina. Es el séptimo productor de vehículos y el quinto exportador de autopartes a nivel mundial. La industria automotriz constituye un sector estratégico de la economía nacional, uno de los ejes del proceso industrial exportador, pues el valor de sus exportaciones es la principal fuente de divisas, representa $21,5 \%$ del total de las exportaciones mexicanas. Este sector de la industria representó en el año 2013 el 15,7\% del PIB manufacturero. Es pertinente preguntarse sobre sus tendencias y modo de operación productiva (INEGI, 2014).

En este contexto de globalización con descentralización productiva, cabe preguntarse cuáles son las características del modelo de organización industrial en el sector automotriz mexicano, cuál es el perfil de las empresas proveedoras, y qué rol cumplen las empresas proveedoras. Considerando la importancia de los procesos de descentra-

\footnotetext{
1 En México la industria automotriz se divide en cuatro segmentos: vehículos ligeros, autopartes, autobuses-camiones-tractocamiones y distribuidores. Existe una amplia literatura sobre el tema, pero la mayoría de estudios incide en la industria terminal dedicada al ensamble de vehículos ligeros. En nuestro caso particular, hemos insistido desde hace años, en el estudio del surgimiento y la consolidación de un fuerte segmento que acompaña a la industria ensambladora terminal: la industria proveedora de Autopartes Algunos estudios se concentran en el análisis de las relaciones de subcontratismo, en particular en la dimensión de las relaciones entre empresas terminales y proveedoras (Juárez, 2005; Daville, 2012; García, 2004). Estudios más recientes incorporan otras dimensiones como las configuraciones sociotécnicas de las empresas no solo terminales sino proveedoras, de alto nivel tecnológico que fabrican componentes y hasta módulos para su posterior ensamblaje en los vehículos. (Arciniega, 2018).
} 
lización y reorganización industrial el objetivo es presentar un panorama general del modelo de organización industrial del sector automotriz en México, incidiendo en el segmento de proveedoras.

Las nuevas características y tendencias de la industria automotriz se enlazan con una nueva división internacional del trabajo o de la producción, que obliga a considerar la evolución de las estrategias espaciales en la industria del automóvil. En esta nueva fase de su evolución se manifiesta una profunda reorganización tecnológica y espacial con estrategias de industria y producción global, políticas integrales que comprenden desde el desplazamiento geográfico con relocalización de actividades, la aparición de nuevas regiones con gran intercambio comercial que facilitan el ingreso de insumos desgravados, y configuración de plataformas de exportación. La descentralización de procesos productivos en otros territorios obliga a considerar el lugar asignado a países en posición de semiperiferias o ahora denominados emergentes, como México, en esta nueva etapa de internacionalización del capital.

También es de destacar los cambios tecnológicos, productivos, socio laborales e institucionales que marcan el periodo, con la generalización de una serie de cambios en los procesos productivos que modificaron las anteriores formas de hacer y organizar en numerosas empresas (Méndez, 1997) ${ }^{2}$. La nueva etapa de transformaciones, en el contexto de la globalización, informa sobre la consolidación de un modelo específico de organización industrial que comprende el aumento de las cuotas de producción obtenidas en establecimientos descentralizados, la separación de algunas producciones y/o actividades de las grandes empresas terminales automotrices y participación de las proveedoras.

El tema es importante debido a que se analiza no solo un sector clave de la economía, sino la reorganización de los tejidos productivos en el país, lo que permitirá analizar la diversidad de caminos de reestructuración al evaluar posibilidades efectivas de desarrollo regional. Por este motivo, se propone la revisión y evaluación de las recientes políticas industriales y laborales. Además, permite incidir también en la discusión sobre los modos de producir, considerando a los países denominados «emergentes» como México donde es posible encontrar sectores industriales como el automotriz, con alto

\footnotetext{
2 El taylorismo supone una creciente racionalización del trabajo según los principios propuestos por Taylor, tendentes a lograr la máxima fragmentación y especialización de la actividad del trabajador manual en operaciones elementales y repetitivas, con control de los tiempos y movimientos de producción, junto a una evaluación constante de los rendimientos para así elevar su productividad. Este sistema, conocido como taylorismo, confluyó en el tiempo con la difusión de nuevos sistemas de organización productiva cuyo origen suele situarse en las factorías Ford de Detroit a partir de 1913, por lo que se les ha identificado con el fordismo. Están basados en una completa mecanización de las tareas, la producción en serie de grandes volúmenes de objetos iguales, y la integración de las diversas etapas del proceso de trabajo en un flujo continuo, a lo largo de una línea o cadena de producción/montaje (Coriat, 1997; Coriat, 1979 en Méndez y Caravaca, 1996).
} 
nivel de tecnología donde es necesario evaluar la calidad del empleo que empresas y gobierno proponen y generan.

La metodología que utilizamos implica la revisión y seguimiento de variables estadísticas de producción, exportación, inversión extranjera directa y empleo. Este trabajo es parte de un estudio más amplio que estudia configuraciones sociotécnicas en empresas proveedoras del sector automotriz. La información que se referencia proviene de resultados de investigación que implicaron revisión de estadísticas sobre la industria automotriz en México, así como literatura desde una perspectiva social, organizacional y territorial sobre las proveedoras. También retomamos información empírica de anteriores trabajos (Arciniega, 2018, 2020). Este trabajo está dividido en tres partes. La primera muestra algunas tendencias en la industria automotriz a nivel internacional y señala la emergencia de nuevas regiones, como México. La segunda presenta a la industria automotriz mexicana: terminales $y$ proveedoras como plataformas de exportación. Finalmente, la tercera parte presenta el perfil de las empresas proveedoras de autopartes.

Como resultado, se presenta un panorama de la industria automotriz en México que intenta contribuir a la comprensión de los procesos de descentralización y reestructuración productiva de esta industria, vinculando sus tendencias y características a las estrategias corporativas de producción global. El enfoque teórico considera la globalización que crea presiones comunes entre los países - tal como la importancia de los procesos de descentralización y reorganización industrial y territorial que incide en el segmento de proveedoras- . Sin embargo, el estudio traspasa una visión simple y determinista de la globalización, y trata de dirigir la atención a las «complementariedades», las instituciones y las políticas públicas con el fin de insertarse posteriormente en la discusión sobre espacios de desarrollo regional y opciones de mejora de condiciones de empleo (Méndez, 2015). En términos teóricos, el presente documento pretende contribuir a la discusión sobre convergencias o divergencias de los modelos productivos y evaluar tendencias y su dirección, hacia vías altas o bajas de desarrollo considerando políticas públicas.

\section{EN EL CONTEXTO DE UNA NUEVA DIVISIÓN INTERNACIONAL DEL TRABAJO EN LA INDUSTRIA AUTOMOTRIZ Y PROCESOS DE DESCENTRALIZACIÓN PRODUCTIVA}

El reciente dinamismo de la industria automotriz mexicana se explica en el contexto de procesos de la globalización, nueva etapa de transformaciones, como una nueva división internacional del trabajo en la industria automotriz internacional. Por este motivo, es necesario revisar las tendencias en la industria automotriz mundial y considerar lo aportado por los procesos de descentralización productiva. 
Por otro lado, ya desde finales de la década de 1980 y principios de la de 1990 el país mostraba indicios de cambio. México atraviesa procesos de reestructuración económica y productiva a partir de esos años, Esta situación se ahondó después de 1994 con la firma del Tratado de Libre Comercio. El lugar que las grandes corporaciones del automóvil asignan a México en la estrategia de producción global coincide con procesos de apertura comercial y la reorientación de la economía mexicana hacia el exterior, previo debilitamiento del anterior modelo sustitutivo de importaciones, cuyos primeros signos aparecen a mediados de las décadas de 1970 y 1980, etapa pasada de estrategias dirigidas hacia el mercado interno y bajo el amparo de las acciones proteccionistas del Estado. A nivel nacional, la apertura del mercado interno impulsó a la inversión extranjera directa la reorientación de la producción hacia el mercado externo o el tránsito a un modelo de país manufacturero-exportador marcan diferencias con un periodo anterior: de mercado protegido marcan el patrón de desarrollo adoptado en esta nueva etapa (Arciniega, 2019c.)

La importancia económica y estratégica que adquiere México en los últimos años puede ser entendida en relación con ambos procesos, en los cuales se resalta una nueva división internacional del trabajo en la industria automotriz, al trasladar las grandes corporaciones automotrices a países semiperiféricos producción manufacturera particularmente intensiva en fuerza de trabajo (Morales, 2005). La actual tendencia hacia una creciente mundialización de los procesos productivos y los mercados refuerza la división del trabajo, la permanencia de relaciones de desigualdad, como la interdependencia entre tendencias globales y respuestas locales, donde las políticas regionales son las que tienden a revalorizar la singularidad de los países (Méndez, 1997, p. 350).

La industria automotriz en México data de los años veinte del siglo pasado y, en el transcurso de los años, ha atravesado diferentes etapas y procesos de reestructuración productiva. Desde fines de la década de 1980 e inicios de la de 1990 la industria automotriz en México muestra una nueva dirección adoptando un perfil exportador y cambio en su estructura interna en el contexto de la apertura de la economía, así como el fin del modelo de sustitución de importaciones y firma del Tratado de Libre Comercio con América del Norte. Después de la crisis del sector automotriz internacional de 2008-2009, repunta y muestra un dinamismo particular. Resaltan la fuerte inversión extranjera directa, la instalación de nuevas plantas terminales y empresas proveedoras, con crecimiento del empleo y aparición de nuevas regiones.

En las últimas décadas se presenta un conjunto de transformaciones no solo en tecnología sino en la organización de la producción y del trabajo. A lo largo de los últimos años las plantas ensambladoras presentan un mayor índice de automatización y han externalizado una serie de actividades configurando una estructura organizacional basada en redes de proveedores con una intensificación y ampliación de las relaciones entre empresas, donde es imprescindible que los proveedores se adapten a las nuevas 
estrategias de las armadoras en lo concerniente a cuestiones tecnológicas y de calidad, donde se impone a las proveedoras producir y entregar sus productos justo a tiempo, pues la tendencia es cero existencias, y con calidad total.

El rol de la industria automotriz de México conjuntamente con otros países denominados emergentes, frente a países desarrollados es bastante estudiado (INEGI, 2014; ProMéxico, 2016). La industria automotriz mundial presenta características novedosas en años recientes A inicios del siglo XXI se presenta un incremento sustancial en la producción de vehículos en el mundo, China se posiciona como primer país productor de vehículos. Por otra parte, es evidente la disminución de la participación mundial de los países tradicionalmente reconocidos como productores, los países más desarrollados, denominados $\mathrm{G}^{3}$ grupo de países conformado por Estados Unidos, Japón, Alemania, Francia, Reino Unido, Italia y Canadá.

En el contexto de globalización, con cambios en la economía internacional asociados con incrementos en el comercio internacional de bienes y servicios, mayores flujos de inversión extranjera directa y mayor número de transacciones financieras internacionales, resaltan las operaciones de las empresas automotrices a nivel de comercio, flujos financieros, creciente capacidad para desplazar la producción de un país a otro, con gran impacto en países como México.

Desde inicios del siglo XXI, la tendencia apunta a disminuir la brecha entre la producción de países desarrollados y semiperiféricos. Se presenta reducción de la producción mundial en los países del G-7 y se incrementa la de países como China, que, a partir de 2009, se posiciona como primer productor de vehículos. Y países denominados «emergentes» como China, Corea del Sur, India, México y Brasil empiezan a incrementar su producción de vehículos y empleo. Ante presiones comunes de la globalización inician procesos de reestructuración productiva y hasta hoy el debate sobre la convergencia o divergencia en los procesos productivos y relaciones de empleo en esos diversos países es motivo de interés.

Un punto de inflexión lo marca la crisis de 2008-2009 en que se registra una disminución de la producción automotriz a nivel mundial, además la producción de los países emergentes supera a los G-7.

\footnotetext{
3 Se denomina Grupo de los Siete (o G7) a un grupo de países cuyo peso político, económico y militar es relevante a escala global. Está conformado por Alemania, Canadá, Estados Unidos, Francia, Italia, Japón y Reino Unido.
} 
Figura 1. Producción de vehículos en países del G7 y emergentes

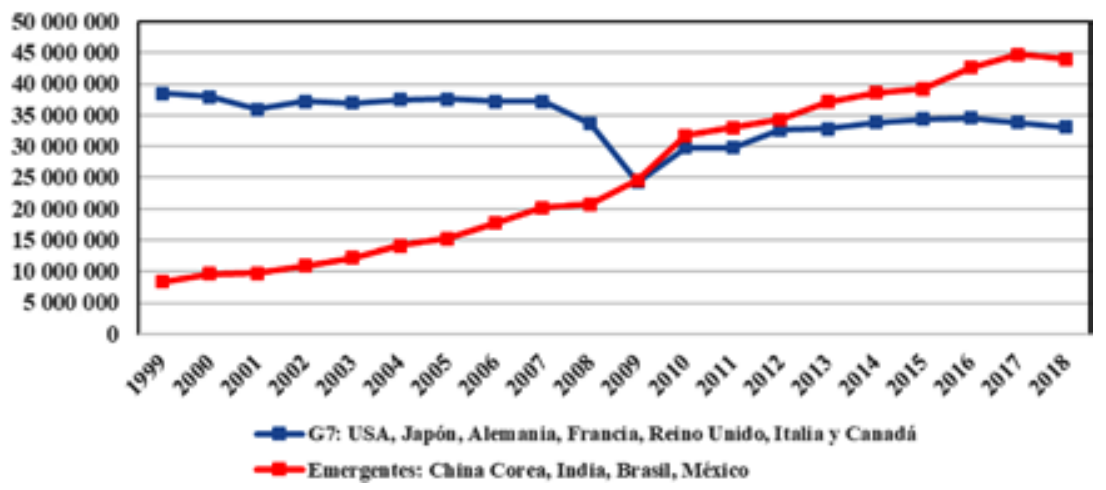

Fuente: Elaboración propia con datos de la Organización Internacional de Constructores de Automóviles OICA (2018).

Así, en el año 2010 se revierte esa tendencia negativa y nuevamente empieza a repuntar la producción. Estos datos se asocian no solo a los lugares que ocupan los países en la producción internacional de vehículos, sino que permiten apreciar las tendencias o estrategias descentralizadoras. Atendiendo a datos de OICA y según lo muestra ProMéxico, se muestra esa relación entre países del G-7 y los países emergentes, donde se encuentra identificado México.

Cambios importantes se pueden apreciar considerando a los países miembros del TLC. Así, si profundizamos en la región América del Norte de 1999 a 2018 México empieza a adquirir importancia como productor automotriz desde la década de 1990, mientras EE. UU. y Canadá simultáneamente reducen su producción, lo que desplaza a México y a Canadá después de la crisis de 2009.

En América Latina, Cono Sur, Brasil y Argentina son los países líderes. Brasil con un rol muy importante como productor hasta 2013. De 1999 a 2013 este país muestra crecimiento. La crisis de 2008-2009 muestra gran caída y dureza en México, no así en Brasil, que sigue creciendo; sin embargo, Brasil ha sido superado por México después de la crisis, a partir, específicamente, de 2013, año en que cae su producción dramáticamente.

Argentina también muestra disminución de su producción en años recientes, además su producción dista bastante de la de Brasil y México. Actividades y fases productivas de las grandes corporaciones parecen tener como sitio preferente a México más que los países del Cono Sur. 
Figura 2. Producción de vehículos Región América-TLC (NAFTA) 1999-2018

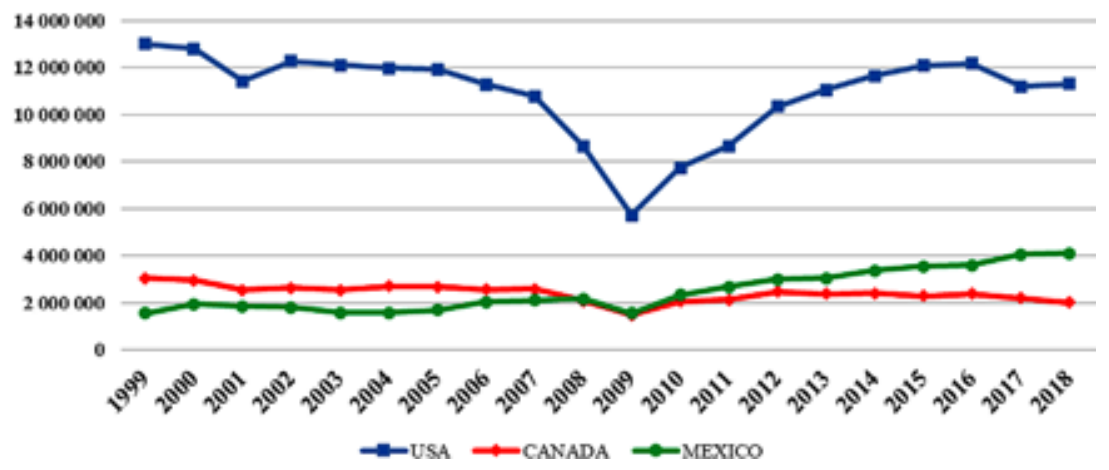

Fuente: Elaboración propia sobre la base de OICA (2018).

Después de la crisis de 2008-2009 repunta la producción de México, y decrece la de Brasil y Argentina. En particular desde 2013 la industria automotriz de México se posiciona como la más importante de América Latina. En México resalta la reorganización geográfica mediante la asignación de relocalización de nuevas empresas, como la llegada de nuevas terminales y proveedoras subcontratistas, se incrementa la producción y el empleo, y se identifica una nueva etapa de «boom de la industria automotriz» a diferencia de sus similares del Cono Sur. Esto marca un cambio en la evolución de las estrategias espaciales en la industria automotriz en la región América.

Figura 3. Producción de vehículos Región América: México-Brasil-Argentina 1999-2018

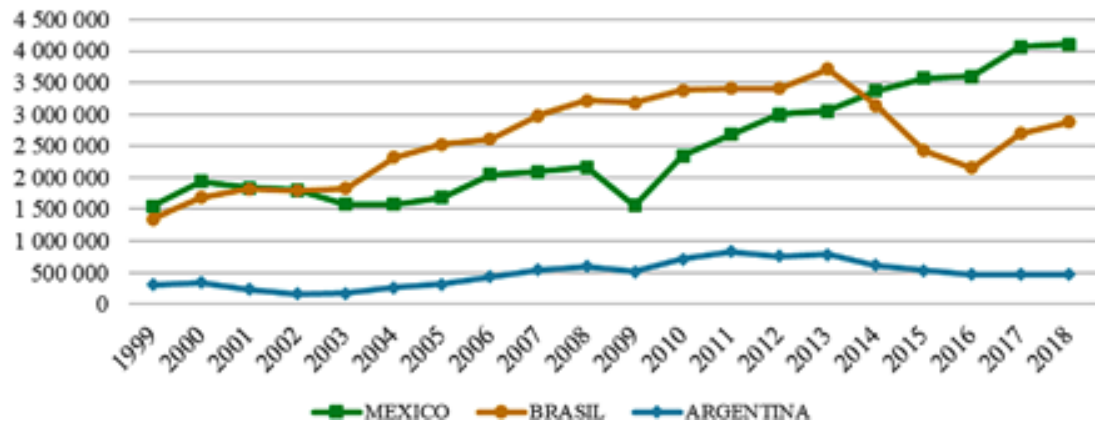

Fuente: Elaboración propia sobre la base de OICA, en Arciniega 2019a. 
Tabla 1. Producción automotriz de vehículos Región América - Año 2017 (unidades)

\begin{tabular}{lrrrrrrrrr}
\hline \multirow{2}{*}{ Región/País } & \multicolumn{2}{c}{2013} & \multicolumn{2}{c}{2014} & \multicolumn{2}{c}{2017} & \multicolumn{2}{c}{2018} \\
& \cline { 2 - 9 } & Unidades & \multicolumn{1}{c}{$\%$} & Unidades & $\%$ & Unidades & $\%$ & Unidades & $\%$ \\
\hline América & 21128805 & 100,0 & 21222463 & 100,0 & 20669537 & 100,0 & 20727528 & 100,0 \\
- NAFTA & 16498633 & 78,1 & 17422866 & 82,1 & 17458189 & 84,5 & 17436070 & 84,1 \\
Estados Unidos & 11066432 & 52,4 & 11660702 & 54,9 & 11189985 & 54,1 & 11314705 & 54,6 \\
México & 3052395 & 14,4 & 3368010 & 15,9 & 4068415 & 19,7 & 4100525 & 19,8 \\
Canadá & 2379806 & 11,3 & 2394154 & 11,3 & 2199789 & 10,6 & 2020840 & 9,7 \\
- América del Sur & 4630172 & 21,9 & 3799597 & 17,9 & 3211348 & 15,5 & 3291458 & 15,9 \\
Brasil & 3712380 & 17,6 & 3146386 & 14,8 & 2699672 & 13,1 & 2879809 & 13,9 \\
Argentina & 791007 & 3,7 & 617329 & 2,9 & 472158 & 2,3 & 466649 & 2,3 \\
Colombia & 74900 & 0,4 & 71137 & 0,3 & 74994 & 0,4 & 0 & 0,0 \\
\hline
\end{tabular}

Fuente: Elaboración propia sobre la base de OICA, en Arciniega, 2019a.

Se presentan procesos de descentralización productiva, con desplazamiento de actividades y fases productivas. En aspectos generales, se presenta un modelo específico de organización industrial, en el cual se asigna un rol diferente a las empresas proveedoras: crece la importancia de la subcontratación, y la empresa terminal o ensambladora encarga a otra subcontratada la realización de piezas, componentes o productos acabados mediante un contrato que incluye una serie de especificaciones técnicas y otras indicaciones complementarias en función de los criterios establecidos por ella. Así, se asumen formas determinadas en los diferentes contextos nacionales.

En México a finales del siglo XX, y hasta la fecha, se consolida este modelo de organización industrial. Diversos estudios analizan la reconfiguración de las cadenas productivas, la cooperación interfirma (Juárez, 2005; García, 2004). Este proceso de descentralización irrumpe, también, a partir de las transformaciones de orden técnico y organizacional, y que repercuten directamente en las relaciones con las empresas proveedoras, pues implican una intensificación y ampliación de las relaciones con estas. De ese modo, los datos estadísticos muestran la importancia de su presencia en el país.

El seguimiento de una variable como la inversión extranjera directa muestra la importancia que va adquiriendo el segmento de proveedores, en el que la cooperación entre las grandes empresas armadoras y las empresas proveedoras de autopartes tienen un sello distintivo. El seguimiento de una variable como el empleo confirman la presencia de un modelo específico de organización industrial, la disociación de tareas antes integradas y el incremento de la división del trabajo, que favorece la presencia de las empresas de autopartes, datos que resaltan la importancia de las proveedoras de autopartes como la organización de redes de vínculos inter e intraempresariales (García, 2004). 
Tabla 2. Inversión extranjera directa en la industria automotriz por segmentos: terminal y de autopartes 2007-2013 (millones de dólares)

\begin{tabular}{|c|c|c|c|c|c|c|c|c|}
\hline IED & 2007 & 2008 & 2009 & 2010 & 2011 & 2012 & 2013 & $\begin{array}{c}\text { Total } \\
\text { período }\end{array}$ \\
\hline \multirow{2}{*}{$\begin{array}{l}\text { Total } \\
\text { nacional }\end{array}$} & 2195,3 & 1690,9 & 1578,3 & 1311,0 & 1260,7 & 2370,0 & 2932,7 & 13338.9 \\
\hline & $100,0 \%$ & $100,0 \%$ & $100,0 \%$ & $100,0 \%$ & $100,0 \%$ & $100,0 \%$ & $100,0 \%$ & $100,0 \%$ \\
\hline \multirow[t]{2}{*}{ Terminal } & 309,6 & 483,0 & 680,3 & 962,2 & 278,0 & 827,4 & 1763,3 & 5303,8 \\
\hline & $14,1 \%$ & $28,6 \%$ & $43,1 \%$ & $73,4 \%$ & $22,1 \%$ & $34,9 \%$ & $60,1 \%$ & $39,8 \%$ \\
\hline \multirow[t]{2}{*}{ Autopartes } & 1885,7 & 1207,9 & 898,0 & 348,8 & 982,7 & 1542,6 & 1169,4 & 8035,1 \\
\hline & $85,9 \%$ & $71,4 \%$ & $56,9 \%$ & $26,6 \%$ & $77,9 \%$ & $65,1 \%$ & $39,9 \%$ & $60,2 \%$ \\
\hline
\end{tabular}

Fuente: Elaboración propia con datos de INEGI, 2014.

Figura 4. IED en la industria automotriz terminal y de autopartes 2007-2013

(millones de dólares)

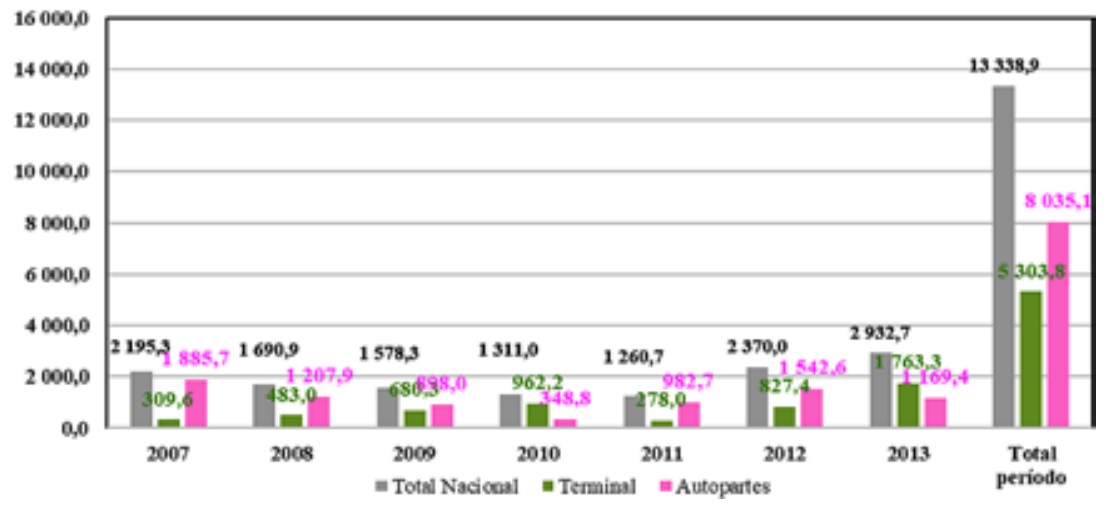

Fuente: Elaboración propia con datos de INEGI, 2014.

En lo referente al empleo, se aprecia que en 2017 son 824000 empleos directos en la industria automotriz - 10,6\% en el segmento de terminales y $89,4 \%$ en el sector de autopartes - L Las corporaciones automotrices terminales han implementado un proceso de externalización de actividades y han adoptado una estructura. 
Figura 5. Personal ocupado en la industria automotriz de México 2003-2017

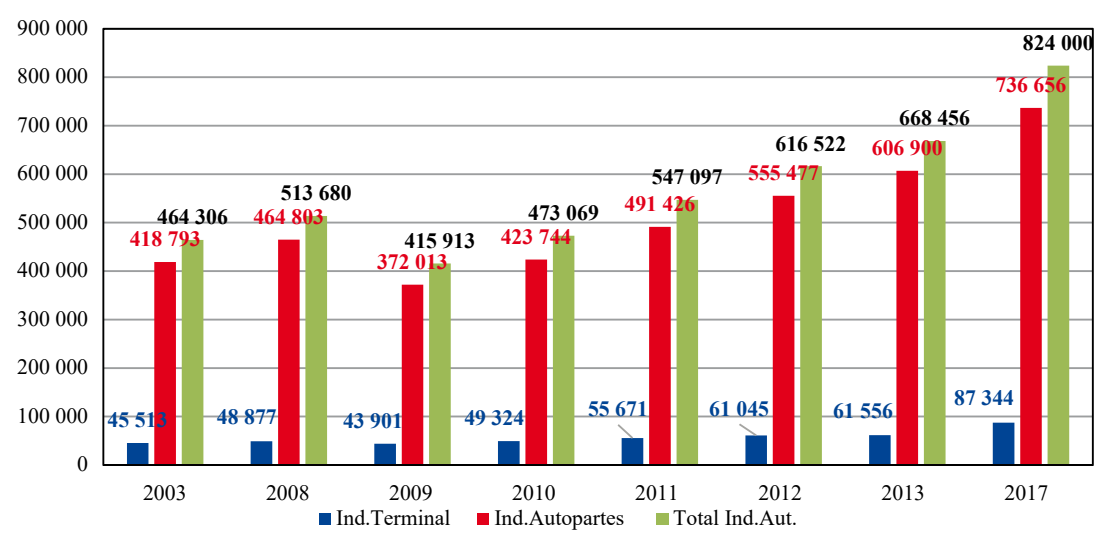

Fuente: Elaboración propia: 2003-2013 con datos de INEGI, 2014, 2017; INEGI-AMIA, 2018.

Las empresas ensambladoras terminales tienen una posición destacada y hegemónica en la industria automotriz, pero ahora la estructura de la empresa red implica resaltar el perfil y la actividad de las empresas proveedoras.

\section{LA INDUSTRIA AUTOMOTRIZ MEXICANA: TERMINALES Y PROVEEDORAS EN EL CONTEXTO DE UNA NUEVA DIVISIÓN INTERNACIONAL DEL TRABAJO}

En 2018, el 88,3\% de la producción de vehículos se destina a la exportación, hacia los países desarrollados de América del Norte.

Tabla 3. Producción y exportación de vehículos ligeros de México 1988-2018 (unidades)

\begin{tabular}{rrcc}
\hline Ańos & Producción & Exportaciones & $\%$ \\
\hline 1988 & 505202 & 172603 & 34,2 \\
1989 & 629230 & 195994 & 31,1 \\
1990 & 803691 & 276859 & 34,4 \\
1991 & 960883 & 358661 & 37,3 \\
1992 & 1051179 & 388739 & 37,0 \\
1993 & 1055221 & 471483 & 44,7 \\
1994 & 1097381 & 567107 & 51,7 \\
1995 & 931178 & 781082 & 83,9 \\
1996 & 1211297 & 975408 & 80,5 \\
1997 & 1338002 & 982952 & 73,5 \\
\hline
\end{tabular}




\begin{tabular}{cccc}
\hline Ańos & Producción & Exportaciones & $\%$ \\
\hline 1998 & 1427590 & 971979 & 68,1 \\
1999 & 1493666 & 1073529 & 71,9 \\
2000 & 1889486 & 1434110 & 75,9 \\
2001 & 1817867 & 1403715 & 77,2 \\
2002 & 1772169 & 1312040 & 74,0 \\
2003 & 1540565 & 1170121 & 76,0 \\
2004 & 1507175 & 1094306 & 72,6 \\
2005 & 1606460 & 1186346 & 73,8 \\
2006 & 1978771 & 1536795 & 77,7 \\
2007 & 2022241 & 1613313 & 79,8 \\
2008 & 2102801 & 1661619 & 79,0 \\
2009 & 1507527 & 1223333 & 81,1 \\
2010 & 2260774 & 1859512 & 82,3 \\
2011 & 2557550 & 2143883 & 83,8 \\
2012 & 2884869 & 2355565 & 81,7 \\
2013 & 2933465 & 2423073 & 82,6 \\
2014 & 3219786 & 2642887 & 82,1 \\
2015 & 3399076 & 2758896 & 81,2 \\
2016 & 3465615 & 2768268 & 79,9 \\
2017 & 3932119 & 3253385 & 82,7 \\
2018 & 3908139 & 3449201 & 88,3 \\
\hline & & & \\
2003 & & 1369 \\
\hline
\end{tabular}

Fuente: Elaboración propia con datos de AMIA en Arciniega (2018).

La industria automotriz mexicana muestra cambios estructurales particularmente desde la segunda mitad de la década de 1980, y después de la firma del TLCAN en 1994. En 1988 en México se producen 505202 vehículos, cuatro ańos después, para 1992 se duplica esa producción a 1051179 vehículos, llegando a inicios de los años 2000 a 1889486 vehículos. En 2007, ya duplica esa producción y llega a 2022241 vehículos. En años posteriores a la crisis de 2008, México presentó un repunte en la producción de vehículos. En 2014 aumentó a 3219786 y, en 2018, a casi 4000000. México se ubica actualmente como el primer país productor de vehículos en América Latina y el séptimo a nivel mundial. 
Figura 6. Producción de vehículos en México 1965-2018 (unidades)

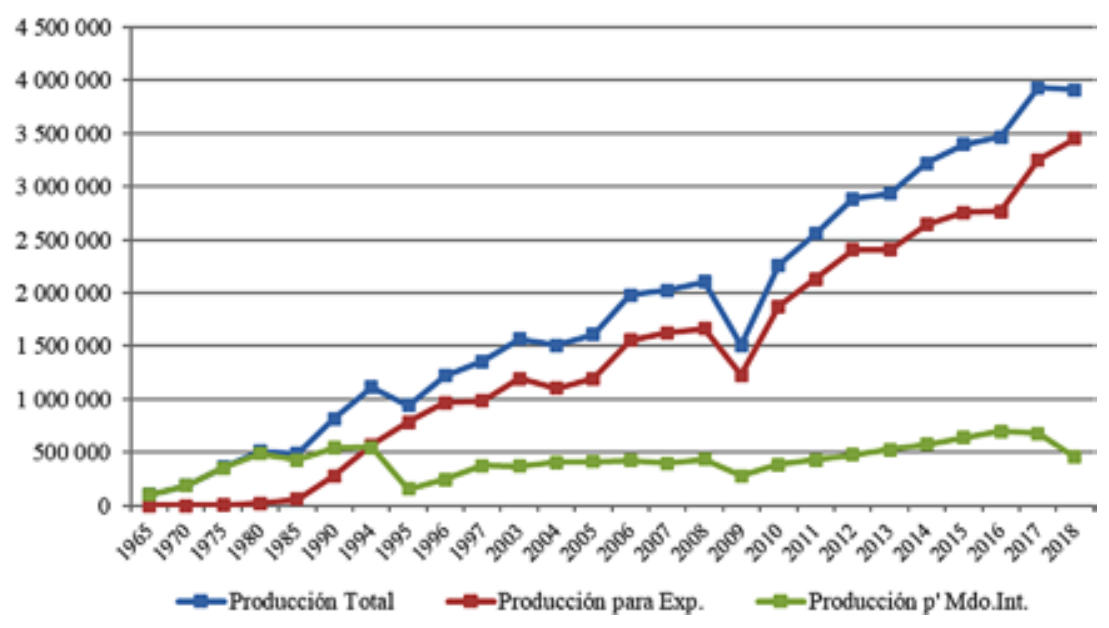

Fuente: Elaboración propia con datos del cuadro anterior.

Si se considera la producción de vehículos por regiones, en la región AméricaNafta, México es el país que presenta una tendencia al alza de la producción; tendencia contraria en los casos de Canadá y Estados Unidos. Entre 2000 y 2018 la producción de vehículos en México se incrementó en 1647365 unidades (72,9\%). En tanto que la producción de sus países socios Estados Unidos y Canadá decreció en ese periodo.

El contexto global da sentido a procesos observados a escala local, sin embargo, es importante no dejar de prestar atención a las condiciones internas de cada territorio, como la política estatal, la estrategia de negocios y la geografía, las instituciones incluidos los sistemas de relaciones industriales, los cuales influyen significativamente en los procesos de internacionalización de la industria automotriz. Autores como Lee y Cason (1994, en Daville, 2012) plantean que la noción de cadenas de mercancías es una herramienta importante para analizar las trayectorias de desarrollo y de movilidad ascendente — vías altas o vías bajas- de los países semiperiféricos.

Las empresas ensambladoras terminales tienen una posición destacada en las pautas de selección de los estados donde se localizan. La fabricación de vehículos constituye el eje organizador del sector; sin embargo, las terminales han tenido que realizar adecuaciones para implementar las nuevas formas de producción. Sus esquemas ya no son la producción en masa, sino una producción flexible, con una amplia capacidad de maniobra. La industria automotriz mexicana está conformada por las empresas terminales —once, en total — y las empresas proveedoras de autopartes —en especial 345 proveedoras directas - de primer nivel o tier one-.

El modelo productivo se basa en la externalización de actividades, donde empresas terminales con el apoyo de las redes de subcontratación por proximidad, proveedoras 
tier one fundamentalmente, surten a sus clientes, justo a tiempo y con calidad total. Esta nueva división del trabajo tiene como exigencia una contigüidad territorial entre terminales y proveedoras para garantizar un ágil sistema de suministro.

Dos características resaltan en la industria automotriz, las empresas han adoptado para obtener ventajas competitivas:

1. El formato organizacional de «empresa-red», la creación de redes de colaboración o de cadena integrada, y una de las formas que han seleccionado para lograr diversos objetivos que solas no pueden lograr o les llevaría más tiempo, es la joint venture; y la producción flexible tanto en terminales como en empresas tier one: La joint venture implica la cooperación sea entre diferentes empresas armadoras, o entre las empresas armadoras y ciertas proveedoras, o bien entre mismas empresas proveedoras ${ }^{4}$. La cooperación entre las grandes empresas armadoras y armadoras proveedoras por medio de los denominados joint venture, es una estrategia de negocios vigente desde las décadas de 1980 y 1990.

2. Las empresas han incorporado la nueva lógica de la producción flexible, por lo que es estrecha la asociación entre la estrategia de producción global y las operaciones de las plantas terminales y proveedoras. Empresas terminales y proveedoras si bien funcionan bajo criterios jerárquicos, también trabajan cooperativamente bajo el modelo lean. Las terminales orientan a los proveedores sobre aspectos técnicos y organizativos y fijan las condiciones estrictas del justo a tiempo y certificaciones de calidad total, apuntando a cero inventarios (Arciniega, 2018), asegurando el nivel de competitividad y productividad que se requiere.

\subsection{Exportaciones de vehículos}

Desde fines de la década de 1980 empieza a cambiar la estructura del destino de la producción de vehículos en México: de producción dirigida fundamentalmente al mercado interno (1926-1988) se transita hacia un mercado de exportación. En México por esos años cambia el modelo de desarrollo, del denominado modelo de industria-

\footnotetext{
4 Joint Venture o aventura conjunta o aventura compartida o riesgo compartido, es un tipo de acuerdo comercial de inversión conjunta a largo plazo entre dos o más empresas. Es un acuerdo para realizar diversos objetivos entre dos o más organizaciones, entre ellos: la creación de un nuevo negocio; el desarrollo de un nuevo producto; la prestación de un servicio; e incursionar en un mercado extranjero. Las empresas implicadas llevan a cabo un negocio o proyecto sin necesidad de modificar sus identidades como empresas, además les permite compartir responsabilidades, riesgos y recursos humanos, financieros y tecnológicos. En este tipo de acuerdos, las organizaciones forman vínculos entre una especie de red salvavidas que alienta a invertir a largo plazo y a compartir riesgos, lo que significa que la integración de redes es una alternativa para sumar esfuerzos y resolver juntos los problemas propios de su actividad, al mismo tiempo, el intercambio de experiencias les permite alcanzar niveles más altos de innovación y desempeño.
} 
lización por sustitución de importaciones, al modelo secundario-exportador, donde la industria automotriz ejerce un rol protagónico. Algunos denominan tránsito de la industrialización doméstica a la transnacionalización (Vieyra, 2005).

En 1985 el volumen de las exportaciones era $12 \%$ de la producción total. Sin embargo, no fue hasta después de 1994, con la firma del TLC que la cifra creció en forma considerable. Para 1995 se incrementa al 79,5\%. En 2013 se destinaron 82,6\% de los vehículos producidos en México al mercado de exportación. En el contexto de transformaciones estructurales en la industria automotriz internacional, México se posiciona como el cuarto exportador de vehículos del mundo. Después de dos países desarrollados (Alemania y Japón), como de Corea del Sur.

Tabla 4. Principales países exportadores de vehículos 2010-2013

\begin{tabular}{llclclr}
\hline \multirow{2}{*}{$\begin{array}{l}\text { Posi- } \\
\text { ción }\end{array}$} & \multicolumn{2}{c}{2010} & & \multicolumn{2}{c}{2011} & \multicolumn{2}{c}{2013} \\
\hline 1 & País & MU & País & MU & País & MU \\
2 & Japón & 4,50 & Alemania & 4,50 & Japón & 4,87 \\
3 & Corea del Sur & 2,80 & Japón & 4,50 & Alemania & 4,75 \\
4 & Espańa & 2,10 & México & 2,10 & México & 2,42 \\
5 & México & 1,90 & Espańa & 2,10 & Espańa & 2,10 \\
6 & Estados Unidos & 1,50 & Estados Unidos & 1,50 & Canadá & 2,06 \\
7 & Reino Unido & 1,00 & Reino Unido & 1,20 & Estados Unidos & 2,05 \\
8 & República Checa & 1,00 & República Checa & 1,00 & Francia & 1,39 \\
9 & Turquía & 0,80 & Turquía & 0,80 & Reino Unido & 1,22 \\
10 & Francia & 0,80 & Francia & 0,80 & República Checa & 1,01 \\
\hline
\end{tabular}

$\mathrm{MU}=$ Millones de unidades

Fuente: Secretaría de Economía (SE) en Arciniega, 2019a.

En cuanto al destino de las exportaciones de vehículos por países, Estados Unidos es el principal receptor de las exportaciones mexicanas (72\% en 2015). Así pues, el mercado de exportación es fundamentalmente regional: entre Estados Unidos y Canadá concentran $83 \%$ en 2015. 
Tabla 5. Destino de las exportaciones de vehículos de México (unidades)

\begin{tabular}{|c|c|c|c|c|c|c|c|c|c|c|}
\hline \multirow{2}{*}{ País } & \multicolumn{2}{|c|}{2008} & \multicolumn{2}{|l|}{2009} & \multicolumn{2}{|l|}{2011} & \multicolumn{2}{|l|}{2014} & \multicolumn{2}{|l|}{2015} \\
\hline & Unidades & $\%$ & Unidades & $\%$ & Unidades & $\%$ & Unidades & $\%$ & Unidades & $\%$ \\
\hline $\begin{array}{l}\text { Estados } \\
\text { Unidos }\end{array}$ & 1175738 & 71 & 878742 & 72 & 1362425 & 64 & 1875575 & 71 & 1993162 & 72 \\
\hline Europa & 213754 & 13 & 126515 & 10 & 220788 & 10 & 98184 & 4 & 145263 & 5 \\
\hline $\begin{array}{l}\text { Latinoa- } \\
\text { mérica }\end{array}$ & 121162 & 7 & 104073 & 9 & 321863 & 15 & 249705 & 9 & 225538 & 8 \\
\hline Canadá & 112606 & 7 & 98949 & 8 & 159440 & 7 & 267371 & 10 & 290340 & 11 \\
\hline Asia & 35976 & 2 & 12333 & 1 & 25538 & 1 & 127171 & 5 & 79902 & 3 \\
\hline Otros & 2383 & 0 & 2721 & 0 & 53825 & 3 & 24881 & 1 & 24691 & 1 \\
\hline TOTAL & 1661619 & 100 & 1223333 & 100 & 2143879 & 100 & 2642887 & 100 & 2758896 & 100 \\
\hline
\end{tabular}

Fuente: AMIA en Arciniega, 2019a.

\subsection{Autopartes en México}

Se configuran redes de empresas. El formato de «empresa-red» se caracteriza por la externalización de innumerables actividades anteriormente desempeñadas por las empresas terminales e implica una intensificación y ampliación de las relaciones con las empresas proveedoras. Esa estructura posibilita a la ensambladora racionalizar sus procesos y ser más flexible ante la inestabilidad de los mercados. El desarrollo de la red de empresas proveedoras automotrices, es el eje central del proceso de reestructuración de la industria automotriz, y por ello constituye nuestra unidad de análisis, resaltando la importancia del estudio del desarrollo y la participación de las empresas de autopartes.

Para 2017 operan en el país más de diez fabricantes de vehículos o empresas ensambladoras terminales, y 1234 empresas de autopartes. Esta industria proveedora se encuentra vinculada mediante encadenamientos productivos tanto a los procesos de las ensambladoras de la región sur de Estados Unidos como a las plantas terminales del territorio nacional, lo que hace que su patrón de localización sea una ventaja más. Es evidente que esta industria se localiza fundamentalmente en los estados del norte del país (Vieyra, 2005, p. 123), y ahora en la región del Bajío.

En la región noroeste (Baja California, Sonora, Sinaloa y Durango) existen 70 empresas proveedoras tier one. En la región noreste (Chihuahua, Coahuila, Nuevo León y Tamaulipas), 198; totalizando el norte 268 empresas. El Bajío (Jalisco, Guanajuato, Aguascalientes, Querétaro, San Luis Potosí, 101. Mientras la región Centro, (DF, Estado de México, Puebla, Tlaxala,) 101 empresas proveedoras de autopartes tier one. 


\subsection{Exportaciones de autopartes}

La industria de autopartes también tiene una alta tendencia exportadora. En 2014, México fue el sexto productor de autopartes a nivel mundial con 81,4 billones de dólares (ProMéxico, Industria Nacional de Autopartes). En 2017 fue el quinto productor a nivel mundial de autopartes (después de China, Estados Unidos, Japón y Alemania) y primero en América Latina. México tuvo un valor récord de producción de 87725 millones de dólares en autopartes en 2017 (AMIA-INA, 2018). La producción de autopartes en México se ha posicionado como una de las más dinámicas y competitivas a nivel mundial (INA, 2014).

El resultado ha sido una mayor integración con el Norte. Ello explica el crecimiento de la inversión extranjera directa y la relocalización de la industria automotriz en México considerando su situación geográfica respecto al mercado o la cercanía a sus principales clientes. Asimismo, las plantas localizadas en el país se configuran como plataforma de exportación. El país se torna estratégico para los inversores interesados en colocar vehículos en Estados Unidos y Canadá, lo que cuenta en las decisiones de localización de las productoras de vehículos, entre otros — costo de mano de obra, por ejemplo-. Después de la crisis de 2008, la tendencia a la exportación se acentúa. Estados Unidos es el principal receptor de las exportaciones mexicanas de autopartes (90,5\% en 2014).

Eso supone, pues, una nueva división del trabajo también entre empresas: empresas red, funciones expulsadas de la gran empresa terminal, subcontratación, con una producción en tiempo real que trata de plegarse a la demanda.

Resalta el nuevo modo de producción de la industria automotriz en México, la producción flexible. La estrategia de producción global en la industria automotriz implica también subcontratar actividades. Las corporaciones automotrices basan su competitividad no solo en la utilización de tecnología flexible, sino en cambios organizacionales, con sistemas de proveeduría determinados y nuevas relaciones entre las empresas. Se apunta a un sistema bien desarrollado de producción por parte de grandes corporaciones integradas flexiblemente. La manufactura automotriz se caracteriza por la reducción de las operaciones realizadas directamente por las armadoras y la transferencia de actividades a empresas proveedoras.

En los últimos años en México es visible el crecimiento de la participación del segmento de autopartes cuya presencia muestra la consolidación de procesos de externalización y configuración de redes, iniciados desde la década de 1990. México es fundamentalmente proveedor de autopartes de Estados Unidos. En lo referente a la inversión extranjera directa (IED) y al empleo, se aprecian cambios estructurales que muestran la adopción de métodos flexibles cuando se subcontratan diferentes procesos y se externalizan innumerables actividades anteriormente desempeñadas por las armadoras. 
Tabla 6. Exportaciones e importaciones de autopartes de México por país, 2014

\begin{tabular}{|c|c|c|c|c|c|}
\hline \multicolumn{3}{|c|}{ Exportaciones } & \multicolumn{3}{|c|}{ Importaciones } \\
\hline País & $\begin{array}{l}\text { Millones de } \\
\text { dólares }\end{array}$ & $\%$ & País & $\begin{array}{l}\text { Millones de } \\
\text { dólares }\end{array}$ & $\%$ \\
\hline Estados Unidos & 58390 & 90,49 & Estados Unidos & 22370 & 53,27 \\
\hline Canadá & 1470 & 2,28 & China & 5409 & 12,88 \\
\hline Brasil & 839 & 1,30 & Japón & 2697 & 6,42 \\
\hline China & 680 & 1,05 & Canadá & 1927 & 4,59 \\
\hline Alemania & 372 & 0,58 & Alemania & 1854 & 4,42 \\
\hline Reino Unido & 349 & 0,54 & Corea del Sur & 1848 & 4,40 \\
\hline Japón & 263 & 0,41 & Brasil & 548 & 1,31 \\
\hline Corea del Sur & 191 & 0,30 & Taiwán & 544 & 1,30 \\
\hline España & 140 & 0,22 & Nicaragua & 496 & 1,18 \\
\hline Nicaragua & 130 & 0,20 & Tailandia & 393 & 0,94 \\
\hline Australia & 126 & 0,20 & Italia & 379 & 0,90 \\
\hline Rusia & 126 & 0,20 & India & 334 & 0,80 \\
\hline Tailandia & 112 & 0,17 & Francia & 332 & 0,79 \\
\hline Argentina & 107 & 0,17 & España & 308 & 0,73 \\
\hline Colombia & 93 & 0,14 & República Checa & 236 & 0,56 \\
\hline Otros & 1139 & 1,77 & Otros & 2317 & 5,52 \\
\hline Total & 64527 & 100,00 & Total & 41992 & 100,00 \\
\hline
\end{tabular}

Fuente: INA, 2014, p. 27 en Arciniega, 2019a.

La IED es importante en las terminales, como también en el segmento de proveedoras. Después de la crisis de 2009, alrededor del 70\% se concentra en el segmento de proveedoras. En cuanto a los salarios se reconoce que son bajos si se les compara internacionalmente, pero son altos si se comparan con otros sectores de la manufactura nacional, y, en cuanto a los empleos, existen núcleos de recursos humanos estratégicos.

En México se encuentran varias filiales de empresas ensambladoras distribuidas en varios lugares de la República. La industria automotriz se localiza en tres regiones: la tradicional región Centro, la región de la frontera Norte y más recientemente resalta la denominada región del Bajío, que comprende los estados de Aguascalientes, Guanajuato, Jalisco, Querétaro y San Luis Potosí.

Atendiendo a la producción, la región Norte concentra en 2008 el $40 \%$ del valor de la producción automotriz nacional, y la región del Bajío, 25\%. En corto tiempo, en 2014, el Bajío concentra el 34,5\% del valor de la producción automotriz nacional. Se presenta como nueva región y se le denomina «el diamante mexicano» por su 
espectacular crecimiento en años recientes y su nivel de infraestructura y grado de conectividad. La tradicional región Centro, antes hegemónica (México, Puebla y Morelos junto con el Distrito Federal), ahora solo representa el 21,4\%, a pesar de la presencia de importantes armadoras y reciente apertura de plantas - como Audi en Puebla- Están perdiendo su lugar en favor de nuevas entidades del territorio nacional.

Si seguimos la variable empleo, el 69\% del empleo se concentra en la región Norte; sin embargo, ya existe una concentración del 17,4\% en la región del Bajío, mientras en la antigua región Centro, antes hegemónica, 17,8\%. En cuanto a la inversión extranjera directa en últimos años: la región Norte concentra el 17\% de la IED, la región Centro 14,9\%, resaltando la región Bajío, con un espectacular 47\% (Véase Arciniega, 2018).

El proceso de relocalización de las plantas obedece a la consolidación de la estrategia de abastecer el mercado externo (market orientation), así gran impacto de la reciente reestructuración productiva de la industria es la emergencia de nuevos escenarios geográfico-productivos automotrices. En el caso de México sobresale la región conocida como del Bajío.

\subsection{Región del Bajío}

En años recientes, la mayor inversión de la industria automotriz en México se ha concentrado en la región del Bajío, conformada por cinco entidades, que son Querétaro, Aguascalientes, Guanajuato, San Luis Potosí y Jalisco ${ }^{5}$. Las plantas automotrices y las proveedoras que se instalan en el país constituyen verdaderas plataformas de exportación, tanto de vehículos como de autopartes y tienden a agruparse como clústeres ${ }^{6}$. El mercado de exportación con exigencias de calidad altas, hace imperioso analizar cómo es que se producen los vehículos.

\footnotetext{
5 Para mayor información sobre la industrialización en la región del Bajío véase Ambriz (2018). Se incide allí en los territorios que comprende el Bajío y se centra en la inversión extranjera directa (IED) en esa región. Añade política federal y estatal mostrando la importancia geoeconómica de dicha región.

${ }^{6}$ Algunos estudios que inciden en la conformación de esta región en México atendiendo a su grado de industrialización y especialización productiva, realizan un análisis espacial de los diferentes clusters que se han formado en el Bajío, véase por ejemplo Unger, Ibarra y Garduño, (2013).
} 
Tabla 7. Localización de plantas terminales en el Bajío

\begin{tabular}{llllc}
\hline \multicolumn{1}{c}{ Estado } & \multicolumn{1}{c}{ Empresa } & \multicolumn{1}{c}{ Origen } & \multicolumn{1}{c}{ Ciudad } & $\begin{array}{c}\text { Año de inicio } \\
\text { de operaciones }\end{array}$ \\
\hline \multirow{2}{*}{ Aguascalientes } & Nissan (Planta 1) & Japón & Aguascalientes & 1982 \\
& Nissan (Planta 2) & Japón & Aguascalientes & 2013 \\
\hline \multirow{2}{*}{ Guanajuato } & General Motors & Estados Unidos & Silao & 1996 \\
& Honda & Japón & Celaya & 2014 \\
& Toyda & Japón & Salamanca & 2014 \\
& VW (motores) & Alemania & Apaseo el Grande & 2019 \\
\multirow{2}{*}{ San Luis Potosín } & General Motors & Estados Unidos & San Luis Potosí & 2012 \\
\cline { 2 - 3 } & BMW & Alemania & San Luis Potosí & 2008 \\
\hline \multirow{2}{*}{ Jalisco } & Honda & Japón & El Salto & 1988 \\
\hline Querétaro & Solo proveedoras & & Ampliación & 2003 \\
\hline
\end{tabular}

Fuente: Elaboración propia con datos de La industria automotriz y de autopartes en San Luis Potosí Secretaría de Desarrollo Económico San Luis Potosí, p.12, en Arciniega, 2019a.

Figura 7. Ubicación de las plantas armadoras en México

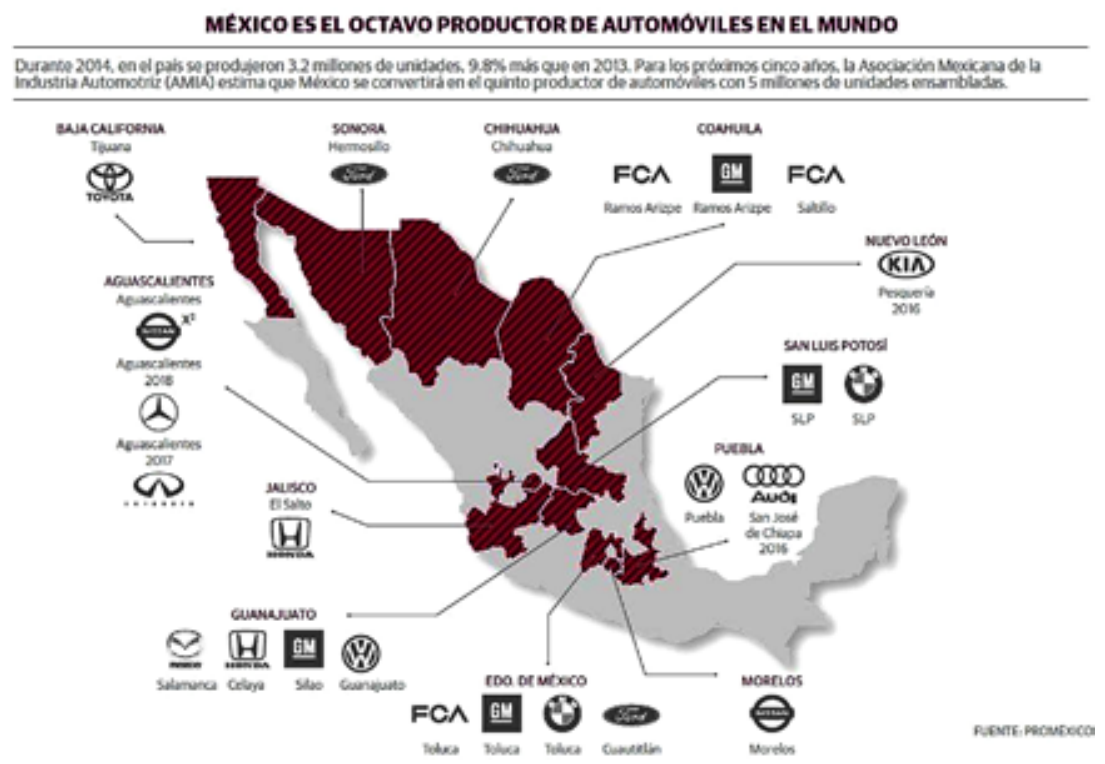

Fuente: ProMéxico, 2016, p. 62. 
Este crecimiento se asocia a la instalación de nuevas empresas ensambladoras o terminales que se han instalado después de la crisis de 2008-2009, en especial empresas japonesas, así como empresas proveedoras americanas, europeas y japonesas, que tratan de fortalecer su penetración al mercado estadounidense.

La preferencia por esa región la muestran la llegada de nuevas empresas, no solo terminales sino proveedoras, especialmente de origen japonés, pero también las alemanas, ello después de la crisis de 2008-2009. Los flujos de comercio entre México y Estados Unidos se intensifican ${ }^{7}$.

\section{LA INDUSTRIA AUTOMOTRIZ MEXICANA: PERFIL DE LAS EMPRESAS PROVEEDORAS}

\subsection{Origen del capital}

En México la mayoría de las proveedoras de autopartes tier one son extranjeras, principalmente son de capital americano, japonés y europeo, son empresas que pertenecen a importantes corporativos extranjeros, que mantienen plantas productivas en diferentes países del mundo. Las proveedoras locales son pocas, pues la tendencia es a concentrar tanto en tier one como de otros niveles a empresas de origen extranjero. Existen pocos productores locales, algunos muy grandes, asociados con capital extranjero, otros pequeños que carecen de capital y recursos tecnológicos para automatizarse según las certificaciones internacionales y son de bajo valor agregado.

\subsection{Jerarquía o niveles (tiers)}

La producción se basa en un sistema de proveeduría. El sistema de proveeduría es jerarquizado, según niveles de vinculación con la terminal o armadora ${ }^{8}$. Este proceso se concentra fundamentalmente en las empresas proveedoras de nivel uno más conocidas como tier one, que suministran directamente a las terminales, sin intermediarios, que cuentan con alta tecnología, son las que venden productos de mayor valor agregado $\mathrm{y}$ tienen un poder de ganancia mayor que las de niveles inferiores. Las tier two les suministran a ellas, las cuales son suministradas por las tier three.

\footnotetext{
7 La producción industrial crece en la región del Bajío, la industria automotriz, junto con la aeronáutica, la han convertido en región prioritaria para el Estado mexicano. Su ubicación geográfica la convierte en punto de encuentro regional (corredor del Bajío) y se le entiende como región que consolida la integración con el Norte atendiendo a una dinámica de desarrollo suprarregional. A las construcciones de vías de comunicación, se agregan plantas generadoras de electricidad, centros de abastecimiento de agua, instalaciones logísticas, etc. Percibido como gigante manufacturero en México y en general en América del Norte.

8 En este sistema existen por lo menos tres niveles de proveedores: un primer nivel de proveedores de sistemas de módulos, un segundo nivel de proveedores especializados en la producción de componentes específicos (por ejemplo, faros, bocinas, etc.) y un tercer nivel de proveedores de partes o piezas de menor elaboración, (por ejemplo, piezas de plástico, piezas eléctricas, etc.).
} 
La presencia de las empresas proveedoras tier one, implica transformaciones estructurales de la manufactura de vehículos. La llegada de estas empresas implicó una fuerte IED. En vez de entregar partes o piezas aisladas, esas empresas pasan a proveer módulos, es decir, subconjuntos listos para el ensamble final. Así, sus clientes son las armadoras de automóviles. El capital extranjero también está presente inclusive en los niveles tier two y tier three.

\subsection{Tamaño}

Las empresas tier one son sobre todo empresas grandes o muy grandes. Resaltan las grandes empresas de capital extranjero. Existen algunas pocas grandes de capital local, proveedoras que, no necesariamente, se concentran en insumos de poco valor agregado. Su presencia no implica formación de cadenas productivas que la enlacen con otros sectores de la industria mexicana, pues datos de balanza de pagos muestran que los lazos son escasos. Y es que esta industria no es simple, requiere gran inversión en capital y tecnología.

\subsection{Producción}

Las empresas proveedoras están dedicadas a la fabricación de partes y componentes varios. Más que una principal línea de producción, proveen una línea de productos bastante diversificada, que comprende desde productos bastante simples que implican actividades intensivas en trabajo tal como arneses, hilos y cables — por ejemplo, cables de encendido-; producen componentes de interiores, accesorios y sistemas eléctricos para automóviles, aire acondicionado, sistemas automotrices, partes plásticas, partes para el sistema eléctrico, partes para el motor y maquinados, hasta productos bastante complejos como módulos de asientos y sus partes, que incluye telas, alfombras; o bien partes para motor y motores; transmisiones, embragues y sus partes, partes y accesorios para carrocerías, ejes y sus partes, bolsas de aire y sus partes; aparatos para aire acondicionado, aparatos de reproducción (audio y video), instrumentos para regulación o control automáticos. Así, fabrican desde productos sencillos hasta complejos, como módulos, tal como asientos y paneles para determinados y diferentes modelos de vehículos. La fabricación modular rige en las proveedoras tier one. Las plantas de una misma filial se especializan en determinado producto.

En busca de ganancias de productividad y de reducción de costos, las terminales procuran mayor participación de las proveedoras a lo largo del proceso de producción. Así pues, se aprecia un mayor involucramiento de las empresas proveedoras de autopartes en diversas etapas del proceso de fabricación del vehículo: proyecto, fabricación y ensamble de partes, en vez de entregar partes o piezas sueltas, esas empresas pasan a proveer subconjuntos listos para el ensamble final la denominada producción modular. 


\subsection{Empleo}

La industria automotriz en México registra un empleo directo de cerca de un millón de trabajadores. La actividad que lidera el empleo dentro de la industria automotriz es la fabricación de autopartes, dando empleo a prácticamente nueve de cada diez personas ocupadas. Si bien esta diferencia resalta desde la década de 1990, la cifra absoluta de población ocupada se ha ido incrementando después de la crisis de 2008-2009. Es importante el empleo en las proveedoras tier one, atendiendo a su personal ocupado. El empleo en el sector automotriz mexicano se concentra en el segmento de autopartes. Este dato muestra este proceso de adelgazamiento y la externalización de la producción de las terminales y como la industria se basa en un sistema de proveeduría que se ha construido y consolidado a lo largo de los últimos años ${ }^{9}$.

\subsection{Instalación en el país}

Las grandes empresas de autopartes cumplen su papel de proveedoras, entrando también —al igual que las armadoras - en operaciones de fusión, adquisición o asociación con otras empresas. Algunas empresas proveedoras tier one datan de etapas anteriores, aquellas que se han estado reestructurando por las estrategias de exportación fundamentalmente dirigidas a Norteamérica, otras datan de los años noventa y otras son muy recientes. No existe un tejido industrial de proveedores nacionales, algunas empresas de origen mexicano están presentes en el circuito, tampoco existe un tejido industrial de proveedores de segundo nivel denso.

\subsection{Ventas}

En ventas ${ }^{10}$ aparecen entre las principales empresas automotrices que sobresalen por sus ventas, proveedoras como Johnson Controls México, Magna International, Lear Corporation, Autoliv México, Bosch México, entre otros. Si bien la mayoría son extranjeras, aparecen algunas de origen mexicano, como Nemak y Metalsa ${ }^{11}$.

\footnotetext{
9 Se delegan funciones en otras empresas, las terminales externalizan actividades productivas, pero también servicios (transporte), inclusive externalizan funciones de mayor valor añadido como son la logística. Para profundizar en la noción como en los procesos de externalización, véase Arciniega, 2020.

${ }^{10}$ En cuanto a las armadoras, sobresalen por sus ventas en primer lugar, General Motors, en segundo lugar, Fiat Chrysler, en tercer lugar, Nissan Mexicana, luego Volkswagen, y en quinto Ford.

${ }^{11}$ Nemak, con sede en Monterrey-Nuevo León, fabrica una amplia gama de partes y sistemas automotrices con un enfoque principal en las partes de automóviles de aluminio, principalmente bloques de motor, culatas y componentes de transmisión. Es un proveedor de Nivel 1 para las principales ensambladoras y se encuentra entre los sesenta proveedores más grandes de la industria automotriz en el mundo. Nemak es una filial del conglomerado industrial mexicano Alfa, que posee el 75,24\% de las acciones de Nemak, mientras que Ford Motor Co. posee el 5,45\% de las acciones y el 19,31\% restante son acciones públicas ofrecidas en la BMV.
} 


\subsection{Clientes}

Las empresas proveedoras tier one tienen como principales clientes a las armadoras instaladas en el país, las perspectivas de su localización actual están vinculadas al mantenimiento de la actividad de éstas (INA, 2014 en Arciniega, 2018).

\subsection{Exportación}

También son exportadoras las plantas de autopartes abastecen tanto a las terminales localizadas en México como también se dirigen a exportación ya que abastecen a otras armadoras instaladas fuera del país. Este segmento de proveedoras se ha fortalecido al conformar una red consolidada de clientes en el mercado exterior. La diferencia la marcan el volumen de entrega, la frecuencia de sus entregas y el plazo de entrega. Las exportaciones de autopartes se dirigen en un 90,49\% a los Estados Unidos, y 2,28\% a Canadá. México es el quinto país exportador de autopartes en 2014, después de Alemania (15\%), China (13\%), Estados Unidos (11\%) y Japón (7\%). Las autopartes que se exportan son fundamentalmente para automóviles hechos en América del Norte.

\subsection{Importaciones}

De acuerdo con INA (2014 en Arciniega, 2018) las empresas de autopartes importan insumos por 41992 millones de dólares y exportan 64527 millones de dólares, esto significa que los encadenamientos productivos con los locales son pocos. Como se ha mencionado, para que una empresa se integre como proveedora de la industria automotriz se requieren procesos de certificación muy exigentes, además la inversión y tecnología son muy altos. Las empresas locales que se encuentran certificadas tier one tienen el perfil de grandes.

\subsection{Configuraciones sociotécnicas}

En estudios recientemente realizados sobre las configuraciones sociotécnicas de empresas terminales como de autopartes tier one, rige la denominada lean production. En terminales y proveedoras tier one, en ambos segmentos se generalizan procesos de producción flexible en las plantas. Las empresas proveedoras se han convertido en agentes centrales en la producción de vehículos bajo la adopción de este modo de producción pues han adoptado prácticas de fabricación flexible, automatización flexible, el sistema de contrapedido, los círculos de calidad, el control estadístico de los procesos, etc. (Arciniega, 2018). 


\subsection{Recursos humanos}

La mayoría de los estudios sobre el tema incide en trabajos simples de los obreros, la oferta de trabajo en las diferentes regiones está compuesta predominantemente por puestos de operarios no calificados, la más baja en la jerarquía del trabajo industrial, jóvenes y con nivel de secundaria. El obrero es entrenado en distintas habilidades, su ascenso se basa en la construcción de la experiencia laboral. La automatización y las modalidades flexibles de trabajo no parecen requerir una gran proporción de trabajadores altamente calificados, solo «núcleos de recursos humanos estratégicos» tal como técnicos, ingenieros, apoyo logístico (Arciniega, 2018).

\subsection{Localización}

Las empresas autopartistas están en veintiún estados de la República. Las proveedoras tier one están especializadas en la producción modular, y por ello buscan estar cercanas a las armadoras, les permite producir justo a tiempo, lo que a su vez es una garantía para las terminales que lo requieren. Uno de los clústeres que resalta en los últimos años es el que se asienta en el Bajío mexicano. En la región del Bajío se han especializado en estampados, componentes eléctricos, frenos y sus partes, productos de hule, partes para motor y transmisión para automóviles. En la región Centro producen asientos, componentes de interiores, aire acondicionado, partes para motor, sistemas eléctricos, gatos hidráulicos tipo botella y suspensión. Es decir, empresas tier one, ya operan con proveeduría modular.

\section{Conclusiones}

Se muestra la importancia de la industria automotriz localizada en México, sus numerosas plantas ensambladoras terminales, así como sus numerosas plantas proveedoras de autopartes tier one con determinado perfil. La contribución más importante del documento es la demostración empírica de la estructura de las empresas automotrices - proveedoras y terminales - y sus redes productivas.

Se incide en un proceso desarrollado en el tiempo, marcado por el Tratado de Libre Comercio de América del Norte (TLCAN), ahora el Tratado México, Estados Unidos y Canadá (TMEC) con el surgimiento y la consolidación de un modelo específico de organización industrial y una nueva organización territorial de la industria automotriz en México, una nueva forma de producir vehículos basada en la descentralización y la externalización, con reconfiguración productiva y una nueva organización territorial. En el contexto de la aprobación del TMEC por los tres países vinculados, el estudio ofrece un panorama de los cambios en la industria automotriz en México.

La relevancia del tema reside en la transición que experimenta Norteamérica con el TMEC. En México se ha discutido desde agosto de 2017 y durante 2018, la 
renegociación del TLCAN, hoy TMEC dándole gran prioridad a la industria automotriz y en particular a este segmento de proveedoras. Por ello, es interesante seguir profundizando en su estudio.

\subsection{Nueva división internacional del trabajo y descentralización productiva. Política de manufactura global}

En el contexto de una economía globalizada resalta el desplazamiento de la producción automotriz de los países desarrollados a los países de menor desarrollo. Se ha creado una nueva división internacional del trabajo al trasladar a los países como México (dependientes o ahora emergentes) plantas de producción manufacturera intensivos en fuerza de trabajo. Se han transformado tanto las condiciones de producción como de localización. La nueva división internacional del trabajo, la inserción en los procesos de globalización, la dinámica productiva, no elimina las asimetrías en la economía internacional ni las diferencias entre países. Comprende la instalación de plantas como plataformas de exportación.

Se constatan procesos de descentralización productiva entendida como la desintegración del proceso productivo en un número creciente de fases y actividades realizadas en establecimientos separados. Se disocian tareas antes integradas y se incrementa la división técnica y espacial del trabajo, favoreciendo la aparición de empresas que actúan como proveedoras, configurando redes de vínculos entre empresas. En México las proveedoras de autopartes adquieren mayor protagonismo.

\subsection{Redes entre empresas terminales y proveedoras}

La importancia de los proveedores de autopartes obedece a la reducción de las operaciones realizadas directamente por las armadoras y la transferencia de actividades a las proveedoras. Este proceso de «adelgazamiento» irrumpe sobre todo a partir de las transformaciones de orden técnico y organizacional adoptadas por las corporaciones automotrices terminales, que repercuten directamente en las relaciones con las empresas proveedoras.

Las nuevas estrategias de las grandes empresas automotrices han modificado la estructura de la industria automotriz mexicana. Desde el Tratado de Libre Comercio la industria automotriz mexicana configura y consolida un formato organizacional basado en las «redes de empresas» donde la competitividad de la producción se basa no solo en alta tecnología, sino en organización de redes entre terminales y proveedoras. Cambios organizacionales, con la subcontratación de segmentos cada vez más amplios del proceso de manufactura son dirigidos por las empresas terminales a empresas proveedoras sobresaliendo las denominadas tier one. 


\subsection{Nueva estructura en el segmento terminal y de proveedoras de autopartes}

Se ha modificado la estructura como la forma de operar de las automotrices. En estas empresas los principios de la organización del trabajo taylorista del trabajo se sustituyen por conceptos de producción flexible, con nuevas formas de organización de la producción y del trabajo. Se combina a nivel de plantas alta tecnología, nuevas formas organizacionales, obreros jóvenes, divididos en calificados, que reciben entrenamiento intensivo y acceden a ascensos dentro de un mercado interno de trabajo, y no calificados, sin experiencia de trabajo, que constituyen la mayoría.

\subsection{Cambios en las estrategias de localización y consolidación de la integración hacia el Norte}

Las formas organizacionales de la producción y del trabajo impactan a nivel territorial. Existe una nueva geografía de la industria automotriz, se ha configurado una nueva región en las últimas décadas. Se presenta la tendencia de la actividad económica a configurar clústeres en las nuevas regiones. Las firmas ensambladoras y proveedoras han cambiado sus estrategias de localización y concentran sus operaciones productivas en los estados del Norte del país, cerca de la frontera con Estados Unidos y más recientemente en la denominada región del Bajío. Nuevas empresas como las japonesas Honda, Mazda, Toyota, y la coreana Kia, inician su vida activa buscando desde el primer momento una localización en aquellas áreas con mejores condiciones actuales para operar, remarcando la nueva organización espacial de la actividad económica. Se reconoce la importancia de su mayor cercanía a uno de los mercados más importantes del mundo, Estados Unidos, como los bajos costos de producción que se tienen en México. Las empresas terminales y proveedoras tier one constituyen plataformas de producción y exportación conjuntas. Tienden a localizarse en las proximidades de su mercado principal (el Norte).

La región Norte y más recientemente, la del Bajío, han tenido una creciente participación en la actividad automotriz, sobre todo a partir de la última fase de estrategias de producción global, lo que ha derivado en un patrón territorial más extenso, pero muy organizado, que desborda la dimensión nacional e integra procesos en una escala de connotaciones transnacionales. Se consolidan clusters y corredores industriales que finalmente sellan la integración con el Norte.

La reestructuración productiva de la industria automotriz a nivel mundial ha impactado en el territorio mexicano de diversas maneras. Han cambiado las condiciones de localización de actividades y con ello la posición relativa de territorios concretos. Este proceso se llevó a cabo por el traslado y nuevo asentamiento de empresas terminales como la instalación de las proveedoras. Los avances en las tecnologías de información y en las comunicaciones en general, permiten a las empresas mantener flujos intensos 
de bienes e información, sea con sus clientes, sea con sus proveedores cercanos como a larga distancia. Se incrementa el comercio con el Norte, los Estados Unidos y Canadá, y también a nivel de la República el comercio intrafirma, que permite a las terminales conseguir una optimización de sus operaciones, al asociar las características del mercado nacional a sus estrategias continentales y globales.

En este contexto de estrategias internacionales de manufactura se remarca la necesidad de estudiar propuestas de políticas de gestión y/o acción productiva local considerando la experiencia espacial del sector industrial automotriz, conocer sus estrategias de movilidad, proximidad, conectividad, si se quiere fortalecer la estructura productiva nacional y el desarrollo sostenible, profundizar en los encadenamientos, fomentar la difusión o generación propia de tecnología, así como proteger el empleo, el mejoramiento de los salarios y calidad del empleo de los trabajadores (Arciniega, 2019b).

\section{REFERENCIAS}

Ambriz, E. (2018). Inversión extranjera directa y crecimiento económico. El caso del sector industrial en el Bajio, 1986-2014 (tesis de doctorado en Estudios Sociales, Línea Procesos Políticos). Universidad Autónoma Metropolitana-Iztapalapa, Ciudad de México, México.

Asociación Mexicana de la Industria Automotriz-AMIA e Industria Nacional de AutopartesINA (2018). Diálogos con la industria automotriz 2018-2024.

Arciniega, R. S. (2018). Reestructuración productiva de la industria automotriz en el estado de México 1994-2016. Ciudad de México: Tirant Humanidades y Universidad Autónoma Metropolitana-Iztapalapa.

Arciniega, R. S. (2019a). Reestructuración territorial de la industria automotriz mexicana 2000-2018 Redes de empresas y nuevas regiones. Ponencia presentada en el XXXII Congreso Internacional de la Asociación Latinoamericana de Sociología (ALAS). Grupo de Trabajo 7: Desarrollo Territorial, Desigualdades y Descentralización. Línea temática 5: Impactos de las actividades productivas en los territorios. Lima, Perú, del 01 al 6 de diciembre de 2019.

Arciniega, R. S. (2019b). Introducción del Tomo 2 del libro Cambio organizacionaly desarrollo sostenible, G. Ramírez et al. (coords.). México: Red Mexicana de Investigadores en Estudios Organizacionales (REMINEO), Grupo Editorial HESS, S.A. de C.V.

Arciniega, R. S. (2019c). Nuevas formas de organización de la producción automotriz mexicana: empresas ensambladoras-proveedoras y su impacto territorial. En G. Ramírez et al. (coords.), Cambio organizacional y desarrollo sostenible, tomo 2. México: Red Mexicana de Investigadores en Estudios Organizacionales (REMINEO), Grupo Editorial HESS, S. A. de C.V.

Arciniega, R. S. (2020). Características de la reestructuración productiva y territorial de la industria automotriz de México: la importancia de la industria de autopartes. En 
G. Ramírez et al. (coords.), Las organizaciones en América Latina. Construcción del desarrollo territorial y regional ante los nuevos entornos internacionales. México: Red Mexicana de Investigadores en Estudios Organizacionales (REMINEO), Grupo Editorial HESS S.A. de C.V.

Coriat, B. (1997). El taller y el cronómetro. Ensayo sobre el taylorismo, el fordismo y la producción en masa. México: Siglo XXI editores.

Coriat, B. (1998). Pensar al revés. Trabajo y organización en la empresa japonesa. México: Siglo XXI editores.

Daville, S. (2012). Arquitectura industrial y reestructuración de la industria automotriz en el Distrito Federal (Ciudad de México) 1993-2010. Revue Interventions économiques [En linea], 46. https://doi.org/10.4000/interventionseconomiques.1829

García, A. (2004). Coordinación inter e intra empresa en la industria automotriz de autopartes: Los casos de algunas plantas de Lear Corporation en México (tesis de doctorado). Universidad Autónoma Metropolitana sede Iztapalapa, División de Ciencias Sociales y Humanidades, Postgrado en Estudios Organizacionales. Ciudad de México, México.

Instituto Nacional de Estadística y Geografía (INEGI) (2014). La industria automotriz en México 2014. México: INEGI.

Instituto Nacional de Estadística y Geografía (INEGI) y Asociación Mexicana de la Industria Automotriz (AMIA) (2018). Conociendo la Industria Automotriz. México: INEGI.

Juárez, H. (2005). La industria proveedora de autopartes. En H. Juárez, A. Lara, C. Bueno (Coords.), El auto global: desarrollo, competencia y cooperación en la industria del automóvil (pp. 71-116). México: BUAP-UAMX-Universidad Iberoamericana-CONACYT.

Méndez, R. (1997). Geografía económica. La lógica espacial del capitalismo global. Barcelona, España: Ariel Geografía.

Méndez, R. (2015). De la globalización capitalista al desarrollo territorial: por una geografía económica socialmente relevante. Scripta Nova, XIX(522). Recuperado de https:// revistes.ub.edu/index.php/ScriptaNova/article/view/15086/18337

Méndez, R. y Caravaca, I. (1996). Organización industrial y territorio. Madrid, España: Síntesis.

Morales, J. (coord.) (2005). México. Tendencias recientes en la geografía industrial. México: Instituto de Geografía-UNAM.

ProMéxico (2016). La industria automotriz mexicana: situación actual, retos y oportunidades. México: ProMéxico.

Unger, K., Ibarra, J. E. y Garduño, R. (2013). Especializaciones reveladas y ventajas competitivas en el Bajio mexicano. Documento de Trabajo E550, CIDE.

Vieyra, A. (2005). Estrategias espaciales de las empresas trasnacionales del automóvil en México. En J. Morales (coord.), México, tendencias recientes en la geografía industrial (pp. 115-129). México: Instituto de Geografía-UNAM. 